\title{
Transcriptome Analysis Reveals Important Transcription Factor Families and Reproductive Biological Processes of Flower Development in Celery (Apium graveolens L.)
}

\author{
Mengyao Li ${ }^{1,+} \mathbb{D}^{\mathbb{D}}$, Shanshan Tan ${ }^{1,+}$, Guofei Tan ${ }^{2}$, Ya Luo ${ }^{1}$, Bo Sun ${ }^{1} \mathbb{D}$, Yong Zhang ${ }^{1}{ }^{1}$, \\ Qing Chen ${ }^{1}\left(\mathbb{D}\right.$, Yan Wang ${ }^{1,3}$, Fen Zhang ${ }^{1}$, Yunting Zhang ${ }^{1,3}$, Yuanxiu Lin ${ }^{1,3}$, \\ Xiaorong Wang ${ }^{1,3}(\mathbb{D}$ and Haoru Tang $1,3, * \mathbb{D}$ \\ 1 College of Horticulture, Sichuan Agricultural University, Chengdu 611130, China; limy@sicau.edu.cn (M.L.); \\ 13551164395@163.com (S.T.); luoya945@163.com (Y.L.); 14099@sicau.edu.cn (B.S.); \\ zhyong@sicau.edu.cn (Y.Z.); supnovel@gmail.com (Q.C.); wangyanwxy@163.com (Y.W.); \\ zhangf_12@163.com (F.Z.); asyunting@sicau.edu.cn (Y.Z.); linyx@sicau.edu.cn (Y.L.); \\ Wangxr@sicau.edu.cn (X.W.) \\ 2 Institute of Horticulture, Guizhou Academy of Agricultural Sciences, Guiyang 550006, China; \\ tgfei@foxmail.com \\ 3 Institute of Pomology and Olericulture, Sichuan Agricultural University, Chengdu 611130, China \\ * Correspondence: htang@sicau.edu.cn \\ + These authors contributed equally to this work.
}

Received: 26 March 2020; Accepted: 1 May 2020; Published: 4 May 2020

\begin{abstract}
There are few reports on the reproductive biology of celery, which produces small flowers in a long flowering period. Anther development was analyzed by paraffin sectioning and related genes were examined by transcriptome sequencing and qPCR. The development process was divided into nine stages based on the significant changes in the cell and tissue morphologies. These stages included: archesporial stage, sporogenous cell stage, microspore mother cell stage, dyad and tetrad stage, mononuclear microspore stage, late uninucleate microspore stage, binuclear cell stage, mature pollen stage, and dehiscence stage. A total of 1074 differentially expressed genes were identified by transcriptome sequencing in the early flower bud, middle flower bud, and early flowering period. Functional annotation indicated that these genes were involved in physiological and biochemical processes such as ribosomes metabolism, sugar metabolism, and amino acid metabolism. Transcription factors such as $\mathrm{C} 2 \mathrm{H} 2$, AP2/ERF, bZIP, WRKY, and MYB played key regulatory roles in anther development and had different regulatory capabilities at various stages. The expression patterns based on qPCR and transcriptome data of the selected transcription factor genes showed consistency, suggesting that these genes played an important role in different flower development stages. These results provide a theoretical basis for molecular breeding of new celery varieties with pollen abortion. Furthermore, they have enriched research on the reproductive biology of celery and the Apiaceae family.
\end{abstract}

Keywords: celery; anther development; cytology; transcriptome sequencing; differentially expressed gene

\section{Introduction}

In flowering plants, the anther is where male gametophytes (pollen) are produced. Anthers of angiosperms are composed of four pollen sacs connected by an anther chamber. The anther wall 
is composed of four layers of cells: the epidermis, the fiber layer, the middle layer, and tapetum, which maintains anther structure and pollen development. Studies have shown that synthesis, accumulation, and degradation of callose occur during anther development. Any abnormality in these steps can lead to anther sterility leading to the production of male-sterile lines [1]. In this context, the use of male-sterile lines as parents for crossbreeding can lead to huge savings in emasculation [2]. The yield of hybrid crops is $20 \%-50 \%$ higher than that of conventional varieties, which can bring huge economic benefits to agriculture [3]. For this reason, male-sterile lines were created in vegetable crops such as Chinese cabbage and radish, and successfully applied to heterosis breeding $[4,5]$. Furthermore, genes leading to infertility have been successively discovered in some major crops $[2,6]$. The introduction of a male-sterility gene into plants through genetic engineering can block, interfere with, or destroy the microspore development process, resulting in male sterility which provides a new idea for plant breeding.

Transcription factor families such as MYB, AP2/ERF, NAC, and MDAS regulate flower development [7-13]. Previous studies showed that abnormal expression of the fertility-related $P h R L$ gene can lead to a significant decrease in pollen viability and enlargement of sexual organs [7]. Sorbitol plays an important role in stamen development and pollen tube growth by regulating the expression of MdMYB39L in apple [8]. Most euAP2 genes in Brassica napus are involved in the regulation of flowering time; they are also highly expressed in flower organs which suggests that they are involved in flower development [9]. The WRKY71 in Arabidopsis thaliana induces flowering by directly promoting the expression of FT (FLOWERING LOCUS T) and LFY (LEAFY) [10]. Studies on chrysanthemum have found that AP2, MYB, WRKY, NAC transcription families regulate carbohydrate metabolism, plant hormone signal transduction, and other processes in flower development [11]. Silencing MADS3 and FBP6 genes by VIGS (virus-induced gene silencing), can induce petunia to form double flowers [12]. A bZIP transcription factor OsTGA10 is necessary for tapestrine development, and mutation of OsTGA10 can lead to male sterility [13]. JAG (JAGGED), which encodes a putative $\mathrm{C} 2 \mathrm{H} 2$ zinc finger transcription factor, can act redundantly with NUB (NUBBIN) to promote the growth of pollen-bearing microsporangia and the carpel walls of the gynoecium [14].

Celery (Apium graveolens L.) is an annual or biennial herb of the genus Apiaceae, native to the Mediterranean region and the Middle East [15]. It is a leafy vegetable crop that is widely cultivated around the world [16]. Celery is rich in nutrients such as proteins, carbohydrates, carotenes, and B vitamins, and also contains a variety of biologically active substances such as apigenin, flavonoids, and terpenes [17]. These substances have a positive effect on hypertension and hyperlipidemia, among other diseases $[17,18]$. As a result of its nutritional and medicinal value, the planting areas of celery are rapidly increasing. In previous studies, some celery varieties with insect pest resistance or disease resistance were cultivated through hybridization and backcrossing. Also, there are some reports about the intergeneric crossings of celery, but their processes are relatively complicated [19]. Therefore, firm guidelines for germplasm improvement and selection of new varieties with improved yield have been proposed. One approach is taking advantage of hybrid vigor or heterosis, however, the small floral organs found in celery lead to difficulties in artificial emasculation. Currently, the efficiency of artificial hybridization of celery is very low, and the lack of male-sterile lines cannot meet its breeding needs [20]. Cultivation of a celery male-sterile line is an important research direction of celery breeding, and some studies on the male-sterile line of celery have been reported. The first celery male-sterile line is the Iranian accession P1229526, which was determined by a single recessive gene, $m s-1$ [21]. The male-sterile plant "01-3A" was identified in the inbred line "01-3" and the report concluded that the male sterility was controlled by two nuclear recessive genes [22]. These reports about the source of CMS (cytoplasmic male sterility) in Apium are not comprehensive. Therefore, we need to produce more comprehensive results. The genome sequence of celery has been published [15], while cytological and biological studies on anther development in celery and Apiaceae plants in general, as well as isolation and cloning of fertility-related genes have rarely been reported. Transcriptional regulation of male-sterility genes in celery has also not been reported. In this 
study, the anatomical structure of the flower development process was studied, and genes related to anther development were evaluated through transcriptome sequencing and expression analysis. Genetic engineering for breeding is of great importance to acquire new celery varieties and improve the quality of celery products.

\section{Materials and Methods}

\subsection{Plant Materials}

Celery variety "Jinnan Shiqin" was planted at the teaching base of Sichuan Agricultural University. The celery flower stages were divided into three stages: early flower bud stage (S1), middle flower bud stage (S2), and early flowering stage (S3) (Figure S1). The flower for each sample (200 mg) of the three stages for RNA sequencing were collected as test materials and immediately frozen in liquid nitrogen, and then stored at $-80^{\circ} \mathrm{C}$, the samples of each stage were set three biological replicates.

\subsection{Cytological Study on Anthers of Celery}

Fresh anthers were used for cytological study. The anthers were divided into nine stages based on their size. They were added to $8 \mathrm{~mL}$ of $50 \%$ FAA fixative solution ( $\mathrm{V}$ formalin: $\mathrm{V}$ glacial acetic acid: V50\% alcohol $=1: 1: 18$ ) and fixed at $4{ }^{\circ} \mathrm{C}$ for $24 \mathrm{~h}$, dehydrated with ethanol and then embedded in paraffin. The thickness of the slice was $5 \mu \mathrm{m}$; safranin O-fast green reagent was used to stain anther tissues. Morphological structure at each developmental stage was observed by optical microscope (Nikon Eclipse Ci, Tokyo, Japan) and photographed [23].

\subsection{RNA Extraction and Transcriptome Sequencing}

Total RNA was extracted from the samples of each stage using the total RNA kit (Tiangen, Beijing, China) according to the manufacturer's instructions. The purity and integrity were tested using the NanoPhotometer spectrophotometer and Agilent 2100 bioanalyzer, respectively. Oligo (dT) was used to enrich the mRNA with a polyA tail. The mRNA was then fragmented and the first strand of cDNA was synthesized with random oligonucleotides and reverse transcriptase. RNaseH and dNTPs were added to synthesize the second strand of cDNA in the DNA polymerase I system. The purified double-stranded cDNA was amplified by PCR and the products were further purified to obtain libraries for Illumina HiSeq 4000 sequencing (Novogene Technologies Co., Ltd., Beijing, China). The transcriptome data were submitted to NCBI under the accession number SRP250986.

\subsection{De Novo Assembly}

Raw data were filtered to obtain clean reads by removing the joint, N-containing, low-quality reads (the base number $Q \leq 20$ accounted for more than $50 \%$ of the entire read length). Assembly of clean reads was performed by Trinity while the contig sequences of each sample were obtained by Overlap [24]. Contig sequences obtained by paired-end were further assembled to obtain the transcripts of each sample. Corset software was used to aggregate transcripts into several clusters based on shared reads among the transcripts [25]. Transcripts with differential expression among the samples were separated from the original cluster to establish a new cluster. The longest cluster sequence was selected as the unigenes for subsequent analysis.

\subsection{Functional Annotation}

Annotation results were obtained by blasting unigenes sequence with $\mathrm{Nr}$ (NCBI protein database), $\mathrm{Nt}$ (NCBI nucleic acid sequence database), Pfam (protein domain annotation classification system), Swiss-Prot database, KOG (lineal homology database), GO (genomic theory database), and KEGG (Kyoto gene and genome encyclopedia database). Blast2GO was used to annotate and classify GO terms. 


\subsection{Analysis of Transcript Abundance and Selection of Differentially Expressed Genes}

Transcript abundance of all unigenes in the three stages was estimated by calculating the read density as fragments per kilobase per million (FPKM). Differentially expressed genes (DEGs) were screened by DESeq2 with the selection criteria set as $\mid \log 2$ (FoldChange) $\mid>1$ and padj $<0.05$ [26]. When the expression of a gene in the two groups of samples was more than double, the differential expression was determined as DEG.

\subsection{Analysis of Transcription Factors for Differentially Expressed Genes}

ITAK software and PlantTFDB (http://planttfdb.cbi.pku.edu.cn) were used to identify celery anther transcription factors and screen different gene transcription factor families for classification [27]. Furthermore, a cluster heat map was drawn to represent the expression of these genes.

\subsection{Verifying Gene Expression Levels by qPCR}

Transcription factor families related to flower development were selected for further analysis of their expression levels at different developmental stages based on their results in DEGs. Double-stranded cDNA samples of celery flower at S1, S2, and S3 stage produced for transcriptome sequencing were used as templates for qPCR. Primer Premier 6.0 was used for designing specific primers. The experiments were performed on a BIO-RAD CFX96 quantitative PCR instrument (Bio-rad, Hercules, CA, USA) according to the method of the SYBR Premix Ex Taq kit (TransGene, Beijing, China). $T U B$ was selected as the reference gene; the relative expression level of genes was calculated using the method of $2^{-\Delta \Delta C T}$ [28]. SPSS23.0 was used for significance analysis and GraphPad Prism 8.0 was used for plotting.

\section{Results}

\subsection{Characteristics of Anther Development in Celery}

Anther development in celery was divided into nine stages. The names of each stage and the corresponding cell morphological changes are shown in Table 1 and Figure 1. Between stages 2 and 3 , the epidermis differentiates to form four anther chambers. Archesporial cells differentiate into primary parietal cells and primary sporophytic cells. The former differentiates into the endothecium (fibrous layer), the middle layer, and the tapetum, whereas the latter divides to form secondary sporoblasts, which can develop into microspore mother cells. At the period of the microspore mother cell, the four-cell layers of the anther which are the tapetum, middle layer, fibrous layer, and epidermis can be seen. Moreover, callose deposition gradually began between the plasma membrane and the primary wall, and further extended from the corner until it surrounded the entire mother cell. With the development of anthers, microspore mother cells underwent meiosis at the fourth and fifth stages, forming dyad and tetrad. At this point, the tapetum had reached its maximum and most active stage while the callose gradually degraded and microspores dissociated. If the callose does not degrade during this period, it will lead to abnormal meiosis, which will affect the release of microspores, resulting in abnormal development of the anther and subsequent formation of male-sterile plants. Following the late uninucleate microspores period, the cells undergo mitosis twice to form a large vegetative cell and two small sperm cells. The pollen sac contained three cells with mature pollen. 
Table 1. Characteristic of developmental stages of celery anthers.

\begin{tabular}{|c|c|c|c|}
\hline Morphological Characteristics of Flower & Anther Stage & Development Stage of Anther & Development Characteristics of Anther Wall and Pollen \\
\hline $\begin{array}{l}\text { The buds are tender yellow and uncracked. } \\
\text { The length of the petals is } 0.05-0.1 \mathrm{~mm}\end{array}$ & 1 & Archesporial stage & The shape of the anther was oval, and the epidermis has formed. \\
\hline $\begin{array}{l}\text { The buds are tender yellow and uncracked. } \\
\text { The length of the petals is } 0.07-0.1 \mathrm{~mm}\end{array}$ & 2 & Sporogenous cell stage & $\begin{array}{c}\text { The anther epidermis gradually differentiated into } 4 \text { anther } \\
\text { chambers, the archesporial cells differentiated into primary parietal } \\
\text { cells and primary sporophytic cells. }\end{array}$ \\
\hline $\begin{array}{l}\text { The buds are yellow-green and uncracked. } \\
\text { The length of the petals is } 0.13-0.16 \mathrm{~mm}\end{array}$ & 3 & Microspore mother cell stage & $\begin{array}{l}\text { From the surface layer of the anther, the tapetum, middle layer, } \\
\text { fiber layer, and epidermis can be clearly seen from the inside to the } \\
\text { outside. As the microspore mother cell develops, thick callose wall } \\
\text { on the surface of the cell continued to thicken and the original } \\
\text { cellulose wall gradually degraded. }\end{array}$ \\
\hline $\begin{array}{l}\text { The buds are turquoise and uncracked. The } \\
\text { length of the petals is } 0.17-0.20 \mathrm{~mm}\end{array}$ & 4 & Dyad and tetrad stage & $\begin{array}{l}\text { Microspore mother cells underwent meiosis to form dyads and } \\
\text { tetrads. The middle cells were squeezed by the tapetum and outer } \\
\text { layers and gradually disappeared. The tapetum cells were the } \\
\text { largest and most active. }\end{array}$ \\
\hline $\begin{array}{l}\text { The buds are pale green and uncracked. The } \\
\text { length of the petals is } 0.18-0.20 \mathrm{~mm}\end{array}$ & 5 & Mononuclear microspore stage & $\begin{array}{l}\text { The callose wall around the tetrad degraded, and the microspores } \\
\text { are freed out and their nucleus is centered with their nuclei } \\
\text { centered. The middle layer cells were almost absent. }\end{array}$ \\
\hline $\begin{array}{l}\text { The buds are pale green and uncracked. The } \\
\text { length of the petals is } 0.20-0.22 \mathrm{~mm}\end{array}$ & 6 & Late uninucleate microspores stage & $\begin{array}{l}\text { The vacuoles in the microspore cells gradually increased to form } \\
\text { larger vacuoles which pushed the nucleus to the edge of the cell. } \\
\text { The tapetum gradually disintegrated. }\end{array}$ \\
\hline $\begin{array}{l}\text { The buds are half-cracked, the petals are pale } \\
\text { white and the length is } 0.22-0.25 \mathrm{~mm}\end{array}$ & 7 & Binuclear cell stage & $\begin{array}{l}\text { The nucleus on the side divided into two nuclei by mitosis and } \\
\text { formed two daughter cells of different sizes. The larger cells were } \\
\text { vegetative cells and the smaller germ cells. The tapetum continued } \\
\text { to decompose and this was the peak of tapetum decomposition. }\end{array}$ \\
\hline $\begin{array}{l}\text { The bud is fully open, the petals are white } \\
\text { and the length is } 0.27-0.29 \mathrm{~mm}\end{array}$ & 8 & Mature pollen stage & $\begin{array}{l}\text { The germ cells of the microspore formed a trinuclear pollen } \\
\text { containing one vegetative cell and two sperm cells through mitosis } \\
\text { The space between the upper and lower chambers deteriorates, } \\
\text { forming two chambers. The tapetum was very small or } \\
\text { disappears completely. }\end{array}$ \\
\hline $\begin{array}{l}\text { The bud is fully open, the petals are white } \\
\text { and the length is } 0.27-0.29 \mathrm{~mm}\end{array}$ & 9 & Dehiscence stage & $\begin{array}{l}\text { The epidermal cells in the stomata area degenerated and the cells } \\
\text { opened causing mature pollen grains to be released. }\end{array}$ \\
\hline
\end{tabular}



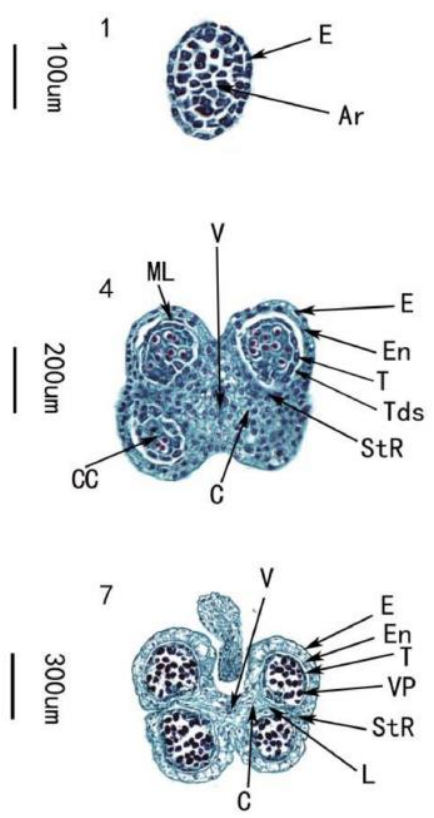
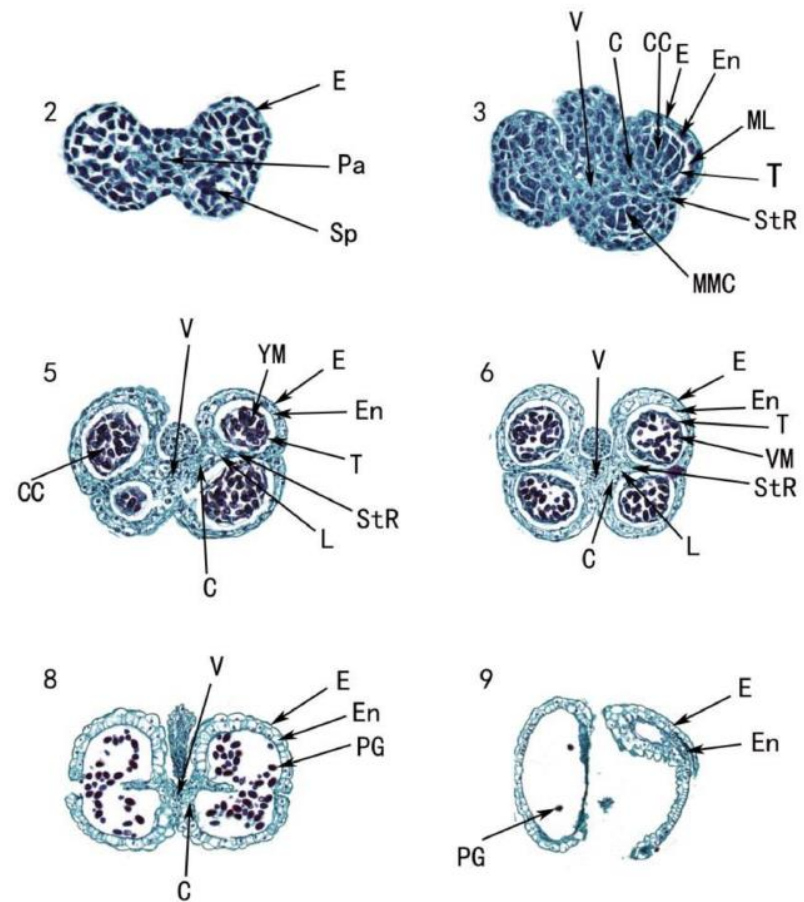

Figure 1. Transverse sections of fixed celery anthers stained with safranin O-fast green reagent at developmental stages 1-9. Pa, Parietal Tissue; Sp, Sporogenous Tissue; E, Epidermis; En, Endothecium; CC, Central Callose; ML, Middle Layer; T, Tapetum; L, Lacunae; StR, Stomium Region; MMC, Microspore Mother Cells; Tds, Tetrads; YM, Young Microspores; VM, Vacuolate Microspores; VP, Vacuolate Pollen; PG, Pollen Grains; V, Vascular Region; C, Connective Tissue. Scale bar is $100 \mu \mathrm{m}$ for stages 1-3, $200 \mu \mathrm{m}$ for stages 4-6 and $300 \mu \mathrm{m}$ stages 7-9.

\subsection{Transcriptome Sequencing and Data Assembly}

To understand the molecular mechanisms behind the progression of flower development in celery, gene expression was analyzed in three flower stages: early flower bud stage (S1), middle flower bud stage (S2), and early flowering stage (S3). A total of 173,094 transcripts were obtained using Trinity and 82,225 unigenes were selected by clustering the transcripts via Corset (Table 2). The length of unigenes ranged from $301 \mathrm{bp}$ to 11,982 bp, the average length was $1117 \mathrm{bp}$, and the length of N50 was $1679 \mathrm{bp}$. Among all unigenes, the range of $300-500 \mathrm{bp}$ accounted for the largest proportion of length, at $32.30 \%$. Unigenes longer than $2000 \mathrm{bp}$ accounted for the smallest proportion of length, at $15.44 \%$.

Table 2. Summary of Illumina transcriptome assembly for celery.

\begin{tabular}{|c|c|c|c|c|}
\hline \multirow{2}{*}{ Length } & \multicolumn{2}{|c|}{ Transcript } & \multicolumn{2}{|c|}{ Unigene } \\
\hline & Number & Percentage & Number & Percentage \\
\hline $300 \mathrm{bp}-500 \mathrm{bp}$ & 41,825 & $24.16 \%$ & 26,560 & $32.30 \%$ \\
\hline $500 \mathrm{bp}-1000 \mathrm{bp}$ & 43,695 & $25.24 \%$ & 23,665 & $28.78 \%$ \\
\hline $1000 b p-2000 b p$ & 52,309 & $30.22 \%$ & 19,301 & $23.47 \%$ \\
\hline$>2000 \mathrm{bp}$ & 35,265 & $20.37 \%$ & 12,699 & $15.44 \%$ \\
\hline Total & \multicolumn{2}{|c|}{173,094} & \multicolumn{2}{|c|}{82,225} \\
\hline Min length (bp) & \multicolumn{2}{|c|}{301} & \multicolumn{2}{|c|}{301} \\
\hline Mean length (bp) & \multicolumn{2}{|c|}{1309} & \multicolumn{2}{|c|}{1117} \\
\hline Median length (bp) & \multicolumn{2}{|c|}{1016} & \multicolumn{2}{|c|}{736} \\
\hline Max length (bp) & \multicolumn{2}{|c|}{11,982} & \multicolumn{2}{|c|}{11,982} \\
\hline N50 (bp) & \multicolumn{2}{|c|}{1864} & \multicolumn{2}{|c|}{1679} \\
\hline
\end{tabular}




\subsection{Functional Annotation for Unigenes}

All unigenes were successfully annotated against seven databases: Nr, Nt, Pfam, KOG, Swiss-Prot, KEGG, and GO. The ratio of successful annotation of each database was obtained which provided a reference for other studies (Table S1) and the functional annotation information of all databases is summarized in Table S2. A total of 39,699 unigenes (48.28\% of total genes) could be characterized by GO annotation (Figure S2): "Biological process" ontology could be assigned to the largest number of genes, followed by "Cellular component" and "Molecular function". In the biological process, the number of genes in cellular processes accounted for the largest proportion, followed by metabolic processes and the single-organism process, and the lowest was cell aggregation. A total of 19,068 (23.19\% of total genes) unigenes had annotation information in KOG database I with 26 categories. These included general function prediction, signal transduction mechanisms, RNA processing and modification, defense mechanisms transcription, and other physiological processes (Figure S3). A total of 17,276 (21.01\% of total genes) unigenes were successfully annotated in the KEGG database with the most frequently represented pathways including Cellular Processes, Environmental Information Processing, and Genetic Information Processing (Figure S4).

\subsection{Identification and Selection of the Differentially Expressed Genes (DEG)}

Using DESeq2 software, 39,218 DEGs were identified in at least one comparison (S1 vs. S2, S1 vs. S3, S2 vs. S3) (Figure 2A and Table S3). The number of DEGs in S1 vs. S3 was the largest, with a total of 19,849 , followed by S2 vs. S3, then S1 vs. S2, with the number of genes being 15,631 and 3738, respectively. There were also 1074 genes that were differentially expressed in the three combinations. All these results suggested that the transcriptome in celery flowers was increasingly different as development progressed. Comparing each combination of the DEGs (including upregulation and downregulation) showed (Figure 2B) that the number of upregulated DEGs was 1,637 and downregulated DEGs were 2,101 at S1 vs. S2. However, the upregulated numbers of S1 vs. S3 and S2 vs. S3 genes were 17,965 and 15,177 , respectively, and downregulated numbers were 1,884 and 454 respectively. This further suggested that differential genes expression was apparent during flower development and, in particular, that an initial reorganization of gene expression was followed by the upregulation of a great number of transcripts in later stages.
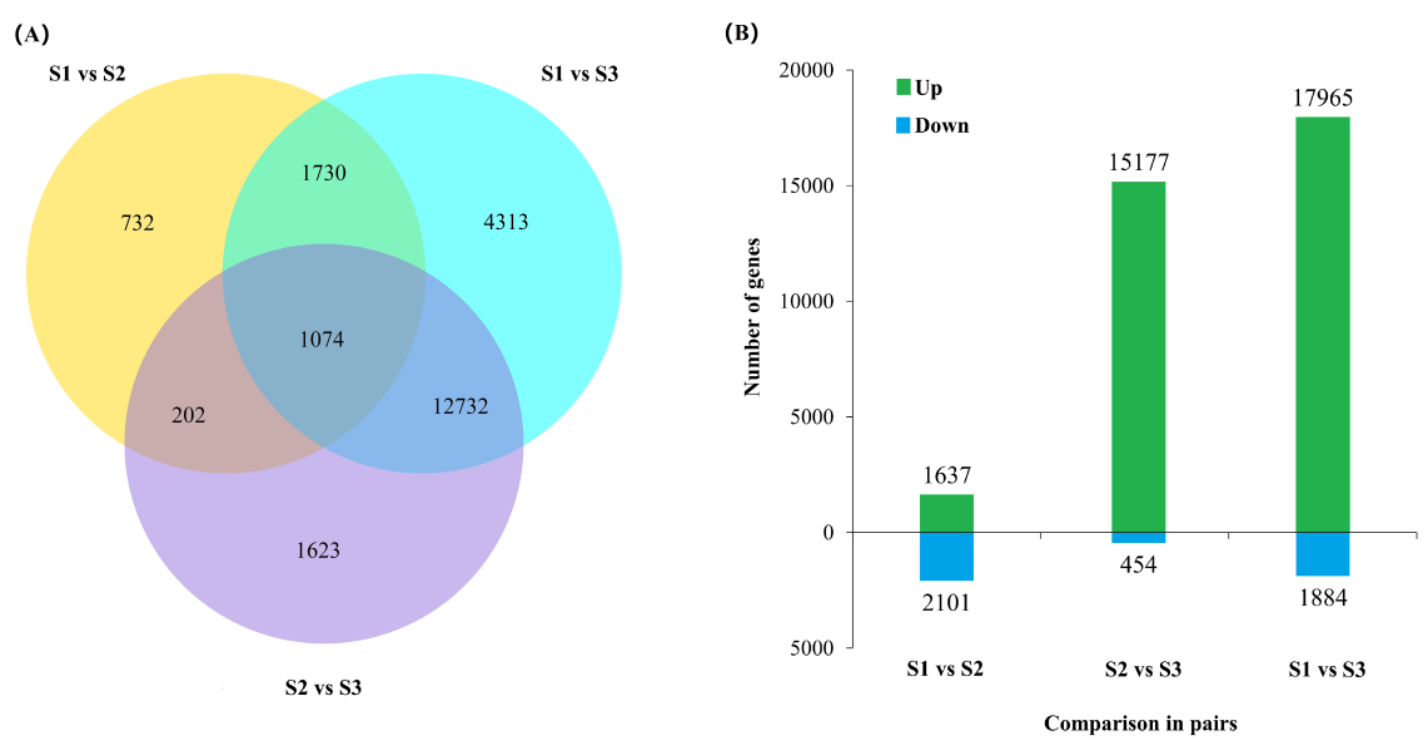

Figure 2. DEGs (differentially expressed genes) in different combinations. (A) Venn diagram of DEGs. (B) Expression levels of DEGs in different combinations at different flower development stages. 
The trend seen in Figure 2B was confirmed when the expression levels of the DEGs were clustered (Figure 3A). Specifically, the expression level of most DEGs was higher in S3 stage than in the S1 and S2 stages. As shown in Figure 3B, the expression level of 1,034 genes steadily increased between the three stages (subcluster 1). These genes were upregulated from S1 to S3 and the increase from S1 to S2 was larger than that from S2 to S3. A total of 4,361 genes were upregulated between S2 and S3 stages (subcluster 2), while the expression levels of 11,339 genes had a slight upward trend (subcluster 3). Moreover, 420 genes showed a slight downward trend from $S 1$ to $S 2$, but were significantly downregulated at S3 (subcluster 4). A total of 229 genes were significantly downregulated from S1 to S2, but not significantly at S3 (subcluster 5). In addition, 5,023 genes were significantly downregulated during $\mathrm{S} 1$ to S2 while upregulated during S3 (subcluster 6). These results further indicate the complexity of gene regulation during celery flower development.

(A)

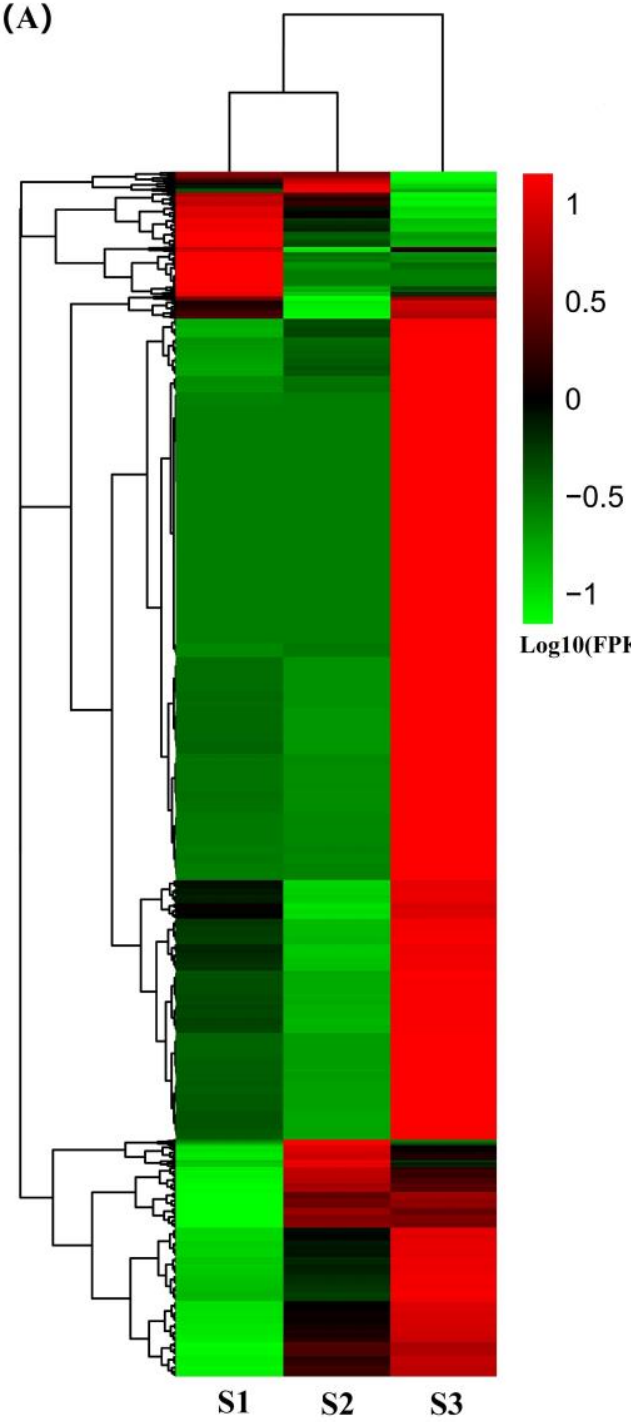

(B)
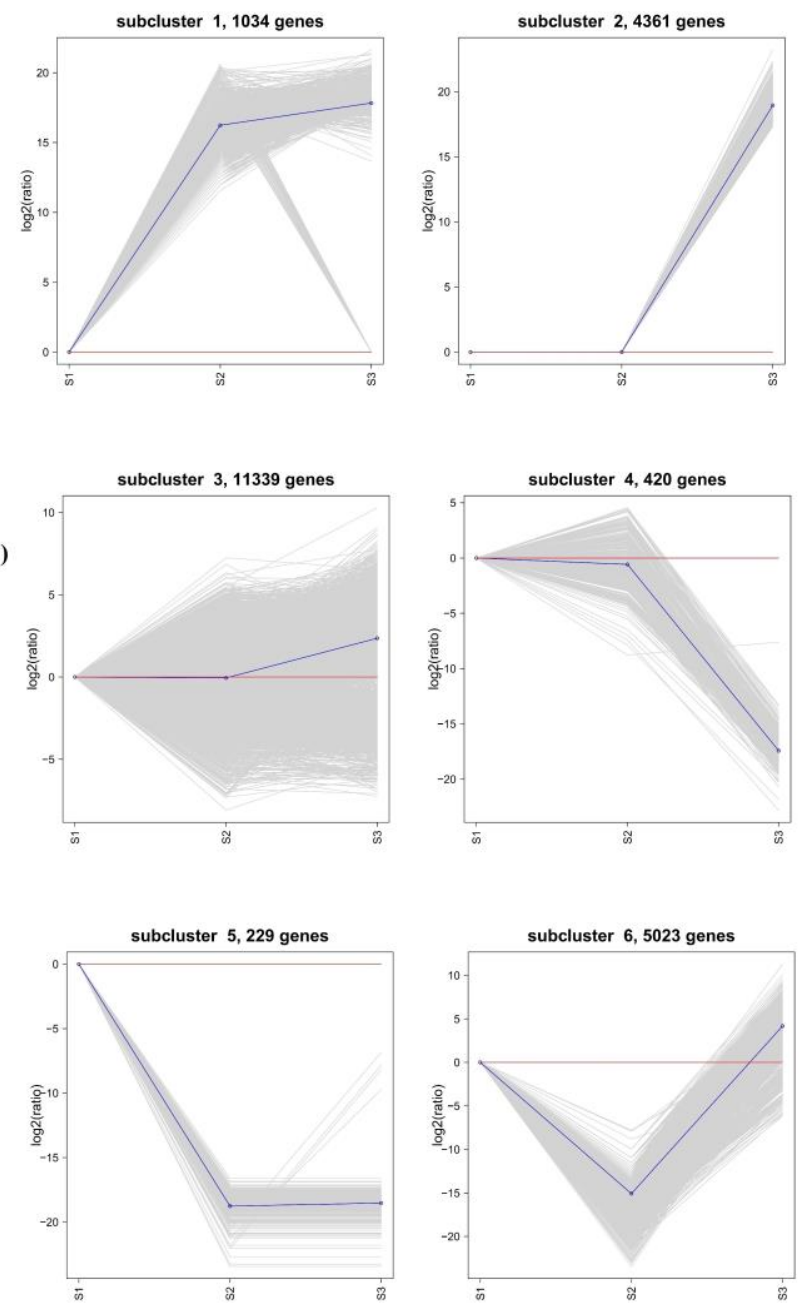

Figure 3. Cluster analysis of DEGs. (A) Cluster analysis of DEGs in heat map. The color represents the transcriptional abundance of the DEGs. Red and green represent high and low expression levels, respectively. (B) Cluster analysis of DEGs in K-means. The gray line represents the expression pattern of genes in each cluster, and the blue line represents the average expression of all genes in the cluster. FPKM (fragments per kilobase per million) values were log10 (FPKM+1)-based in (A) and FPKM values were log2-based in (B). 


\subsection{Functional Annotation of Differentially Expressed Genes}

To further study the biological significance of gene variation between flower development stages, GO and KEGG database analyses were performed. Figure 4 shows that in the biological process, the DEGs were enriched in chitin and glucosamine-containing compound metabolic processes. DEGs were significantly enriched in S1 vs. S3 and S2 vs. S3 were associated with the amino sugar metabolic process. DEGs that were significantly enriched in S1 vs. S2 and S1 vs. S3 were linked to the ribonucleoprotein complex and ribosome biosynthesis, while DEGs significantly enriched in S1 vs. S3 participated in the lipid transport process. DEGs that were significantly enriched in S1 vs. S3 and S2 vs. S3 were associated with the cytoplasm and cytoplasmic part. DEGs found to be significantly enriched in $\mathrm{S} 1$ vs. S2 and S1 vs. S3 were involved in extracellular regions, ribonucleoprotein complexes, ribosomes, and extracellular regions. DEGs found to be significantly enriched in S2 vs. S3 were involved in threonine-type endopeptidase activity and threonine-type peptidase activity, while those significantly enriched in S1 vs. S2, S1 vs. S3, and S2 vs. S3 were associated with the structural constituent of cuticle, structural molecular activity, and chitin binding.

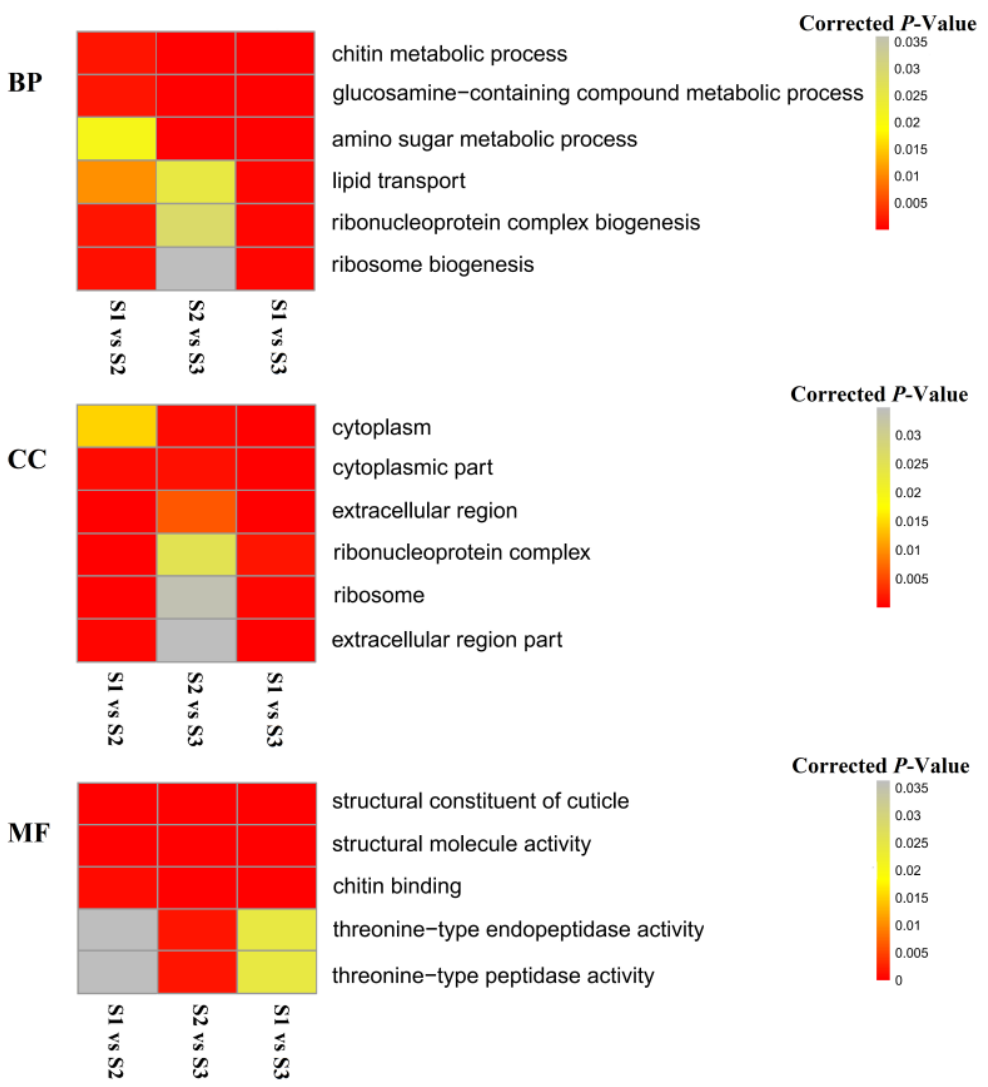

Figure 4. GO (genomic theory database) enrichment analysis of DEGs. BP, Biological Process; CC, Cellular Component; MF, Molecular Function. Corrected $p$-Value $<0.05$ represents enrichment, the smaller the $p$-Value, the closer the color is to red and the more significant the enrichment.

Figure 5 reveals that KEGG annotations for the three pairs (S1 vs. S2, S1 vs. S3, and S2 vs. S3) were significantly enriched in proteasome and ribosome pathways. DEGs that were significantly enriched in S1 vs. S2 were involved in oxidative phosphorylation, carbon fixation in photosynthetic organisms, pentose and glucuronate interconversions, plant-pathogen interaction, pentose phosphate pathway, glycolysis/gluconeogenesis, and other metabolic processes. We speculate that these processes regulated nutrients levels during anther development. There was no obvious enrichment in these processes in S1 vs. S3 and S2 vs. S3. In contrast, DEGs that were not enriched in S1 vs. S3 and S2 vs. S3 were associated with processes that regulate nutrients levels and were enriched in the 
phagosome and spliceosome processes. DEGs found to be only enriched in S2 vs. S3 were linked to the N-glycan biosynthesis, mRNA monitoring pathway, protein processing in endoplasmic reticulum, purine metabolism, pyrimidine metabolism, DNA replication, and other processes.
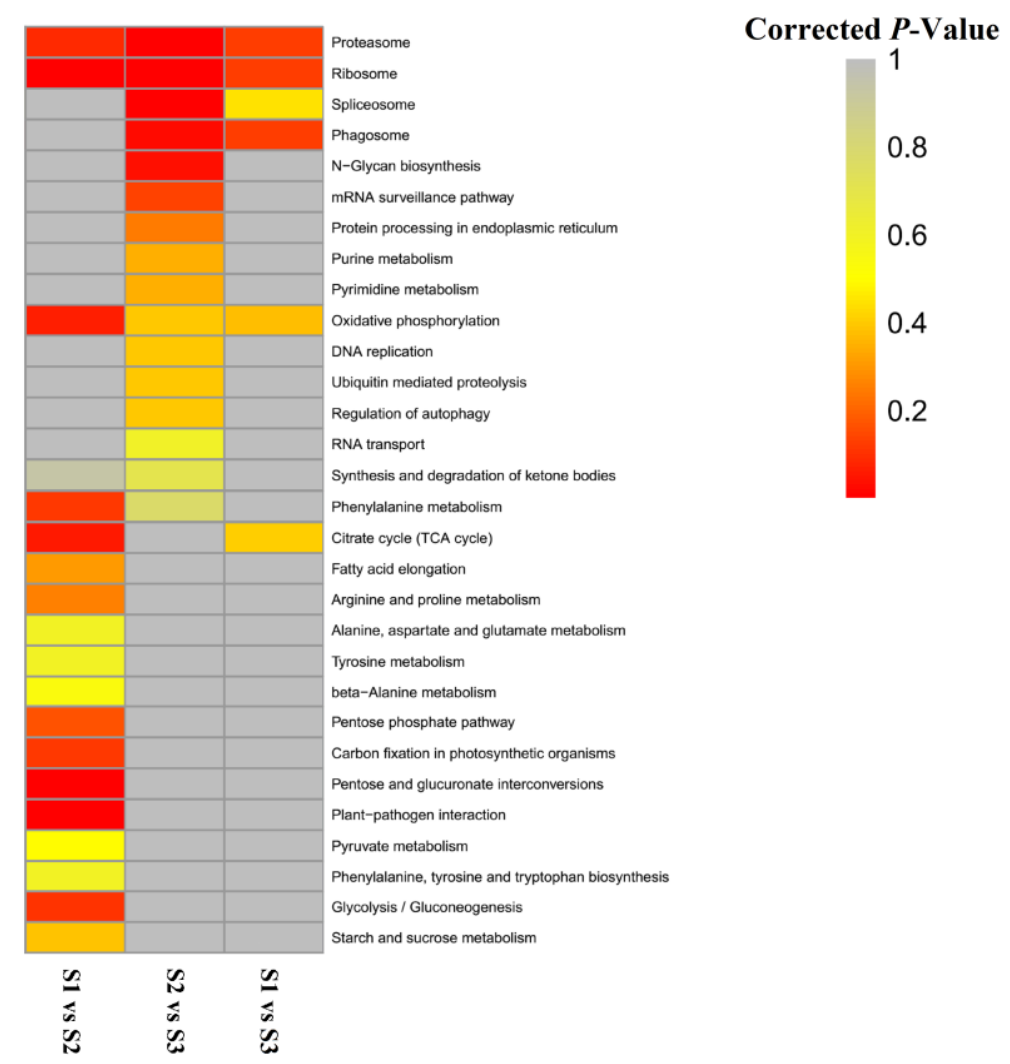

Figure 5. KEGG (Kyoto gene and genome encyclopedia database) enrichment analysis of DEGs.

The smaller the $p$-Value, the closer the color is to red and the more significant the enrichment.

\subsection{Analysis of Transcription Factors Regulated by the DEGs}

In this study, we analyzed the transcription factors for the DEGs and named them using the transcription factor family information found in the plant transcription factor database. A total of 558 differential TFs were classified into 34 transcription factor families: C2H2, AP2/ERF, bHLH, bZIP, WRKY, MYB, MADS-M-type, etc. (Figure 6A). A heat map drawn from the gene expression levels of each transcription factor family member (Figure 6B) shows that AP2/ERF and GRAS were highly expressed in the three stages, while $\mathrm{C} 2 \mathrm{H} 2$ and TCP were generally lowly expressed in the three stages. The expression levels of WRKY, MYB, AP2/ERF, and some other transcription families at S1 stage were relatively high, but their expression level patterns showed a downward trend at $\mathrm{S} 2$ and $\mathrm{S} 3$ stages. At $\mathrm{S} 1$ stage, the expression levels of bZIP, MADS-MIKC, and MADS-M-type were relatively low but the level of these transcription factors generally increased in S2 and S3 stages. Notably, PHD and NF-YC family genes were not significantly expressed at stages $\mathrm{S} 1$ and $\mathrm{S} 2$, but they were upregulated at stage S3. These results indicated that each stage of flower development was associated with different TFs. In addition, it was also found that the number of members in PHD, C2H2, HB-other, AP2/ERF, and $\mathrm{C} 3 \mathrm{H}$ in celery accounted for a higher proportion of the corresponding TF family members. 


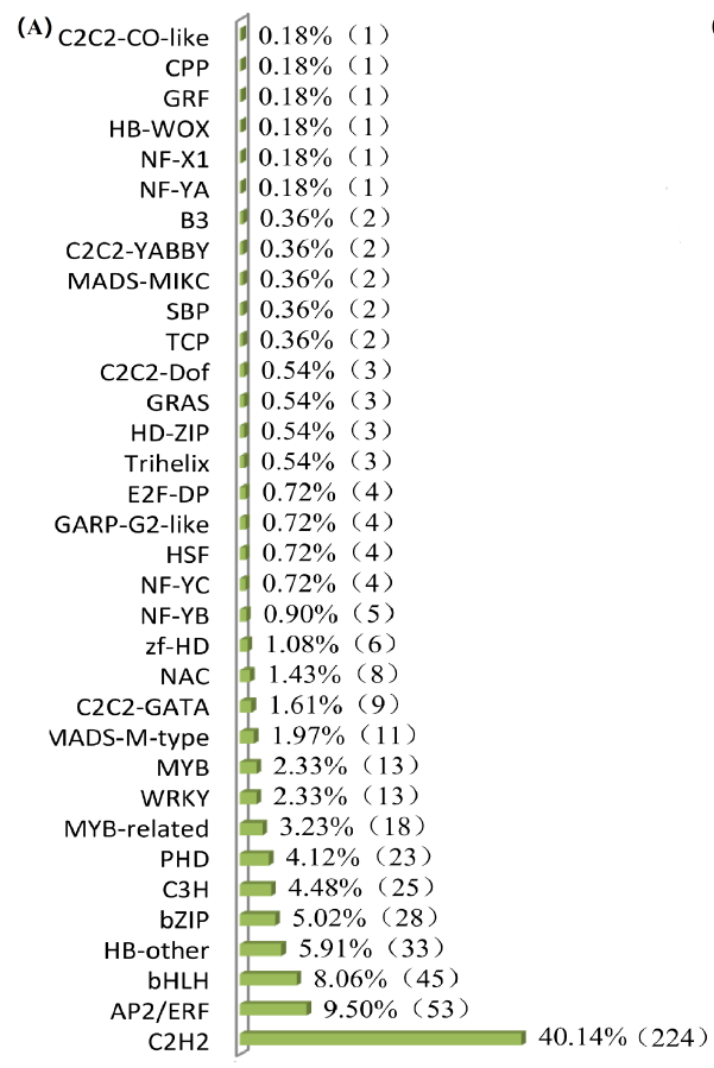

(B)

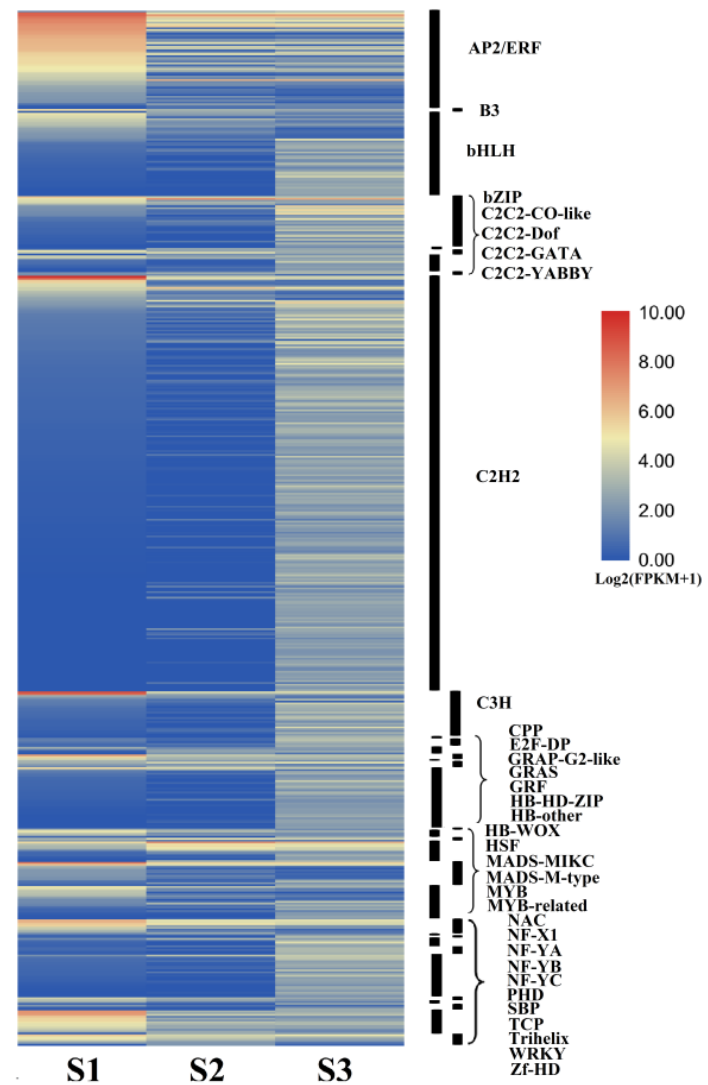

Figure 6. Analysis of transcription factors of DEGs. (A) Statistics of transcription factor families. Percentage refers to the ratio of the number of members of each transcription factor family to the total number of members of all celery transcription factors. (B) Expression of transcription factors at different flower development stages. FPKM-values were log2 (FPKM+1)-based. Red, yellow, and blue represent high, medium, and low expression levels, respectively.

\subsection{Verifying Gene Expression Levels by $q P C R$}

Gene expression was validated using qPCR for the members of five transcription factor families associated with flower development: AP2/ERF (Agr25217, Agr13446, Agr00157, Agr14035); WRKY (Agr18589, Agr36822, Agr19214, Agr14189); bZIP (Agr39039, Agr05322, Agr12243, Agr01062); MASD-M-type (Agr17559, Agr08149, Agr37458); and C2H2 (Agr04312, Agr28404, Agr30688). Figure 7 shows that results of qPCR analysis and transcriptome sequencing were consistent in terms of expression trends during flower development.

Notably, the transcriptional abundance and expression of Agr14035 were higher in S1, lower in S2 and S3, while those of Agr 25217 were downregulated across the three stages. The expression level of Agr13446 was downregulated by at least four times from S1 to S2, and was upregulated at least two times from S2 to S3.

The expression levels of WRKY family genes (Agr14189, Agr36822, and Agr19214) were significantly different at three stages of flower development. Of note, they were significantly altered in the early flower bud stage, but not significantly altered in between middle flower bud and early flowering stage. The expression levels of Agr 14189 decreased by seven-fold from early flower bud to middle flower bud stage, while that of Agr36822 and Agr19214 decreased at least 20 times and 4 times, respectively.

The expression of Agr05322 was similar across the three stages but Agr01062 tended to decline across the three stages. The expression of Agr39039 decreased from S1 to S2 and then increased from S2 to S3, which matched with changes in the corresponding transcriptional level. 
(A)
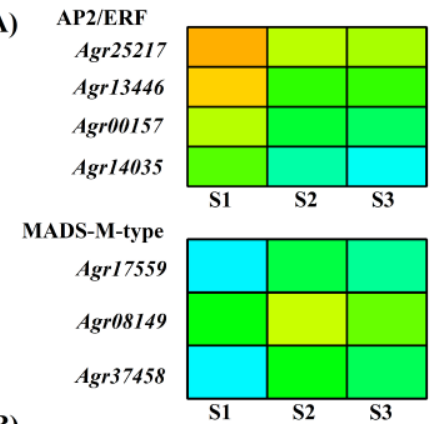

(B)
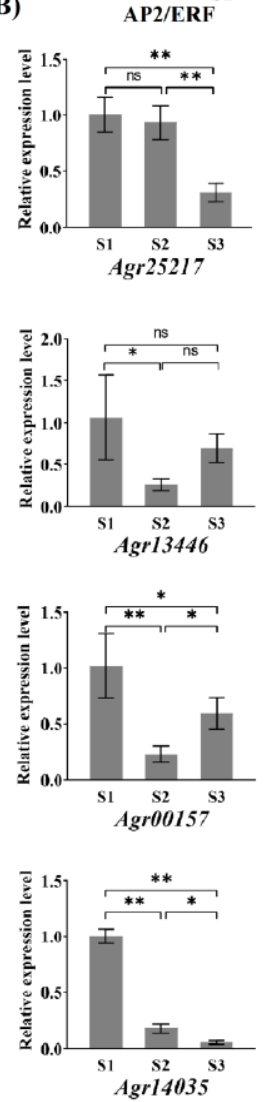
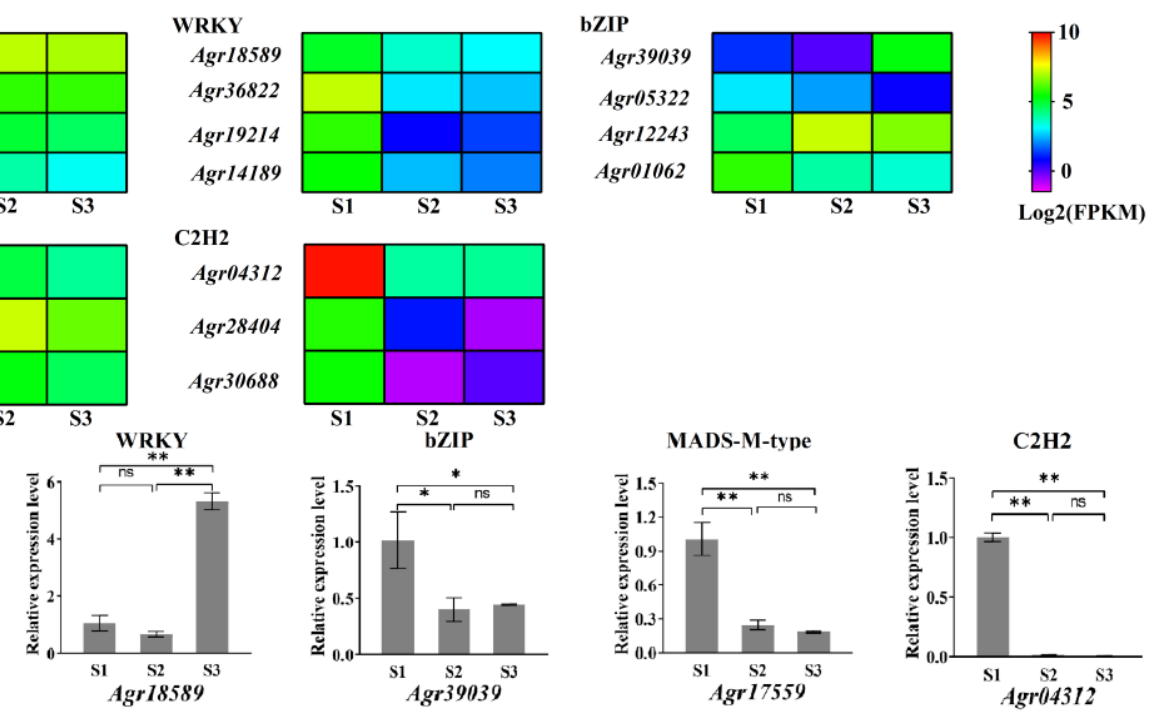

${ }_{\text {Agr04312 }}^{\mathrm{C} 2 \mathrm{H} 2}$

Agr28404

Agr3068
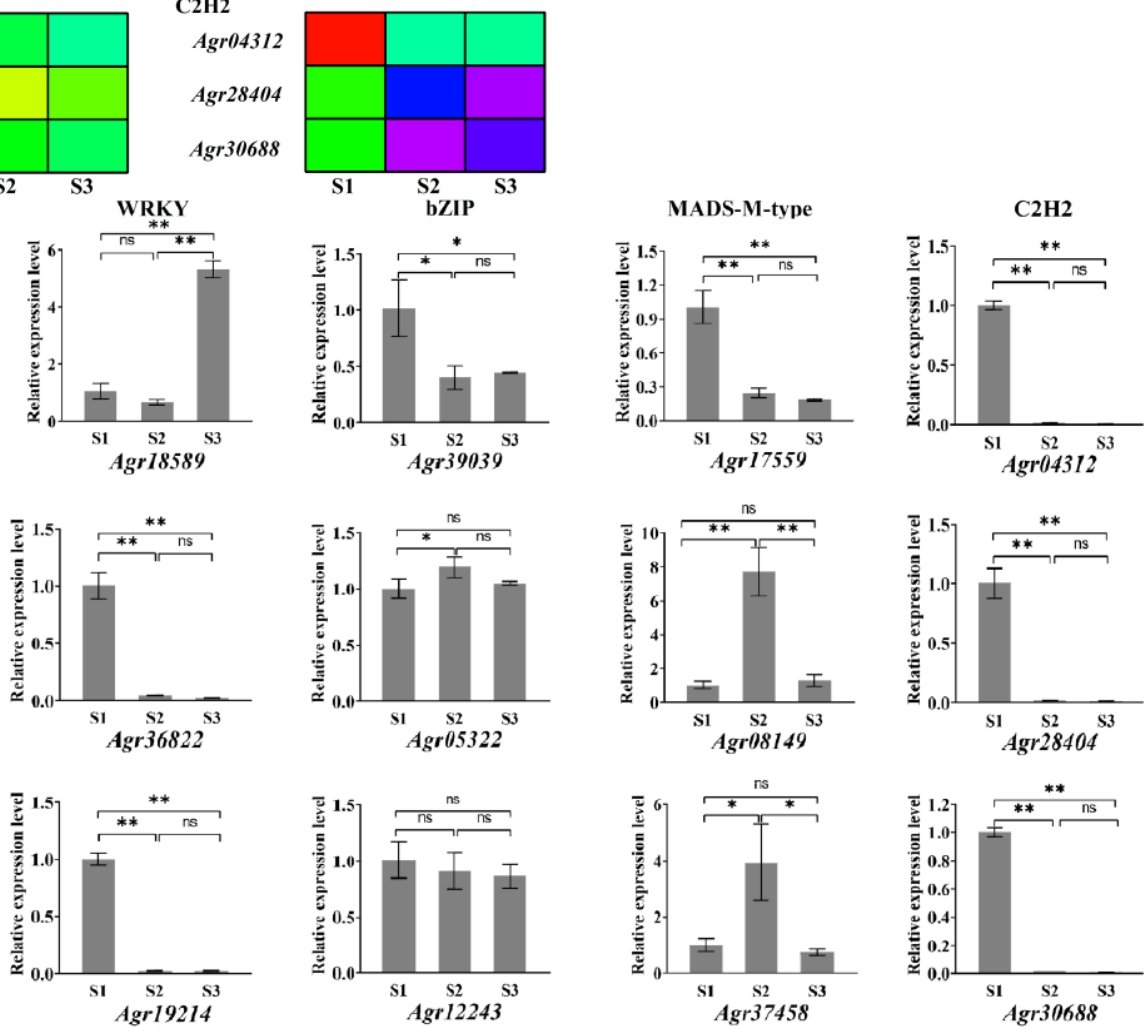

Figure 7. Cluster analysis of transcription abundance and the results of relative expression level of verified genes at different flower development stages. (A) Heat map showing transcriptional abundance of DEGs. FPKM-values were log2-based. (B) Relative expression level of genes detected by qPCR. The data are presented as the mean \pm SD of three biological and technical replicates.

The expression level of Agr08149 in the MADS-M-type family was upregulated by seven times in S1 compared to S2, reaching the highest expression level at S2, but it was downregulated by at least five times at S3 compared to S2. The expression level of Agr37458 was upregulated by three times in S1 compared to S2, being highest in S2, and was downregulated by five times in S3 compared to S2. The expression levels of these two genes changed significantly from early flower bud stage to early flowering stage implying that they have important roles in celery flower development.

The expression level of the three genes in the $\mathrm{C} 2 \mathrm{H} 2$ transcription family were significantly upregulated from S1 to S2, of which Agr 04312 was upregulated by approximately 85-fold, and Agr 28404 and Agr30688 were upregulated by at least 50 and 60 times, respectively. At S2 and S3, all of their expression levels were very low and did not alter significantly. 


\section{Discussion}

\subsection{Characteristics of Changes during Anther Development}

In angiosperms, flower development is the most important reproductive growth process of plants. The anther is the major pollen-producing part of the plant whose development greatly relies on its fertility. Development of plant anthers is a continuous process related to corresponding cellular processes, such as meiosis, mitosis, the formation of anther walls, development of tapetum cells, and dynamic changes of callose $[29,30]$. When tapetum cells of the anther develop to a certain stage, they need to be degraded by programmed cell death to provide nutrition and materials needed for the development of microspores. If the degradation of tapetum cells is advanced or delayed, it would lead to male sterility [31]. Previous studies have shown that impaired callose synthesis, accumulation, and degradation would lead to the failure of meiosis and ultimately affect plant fertility [32]. It is of great importance to distinguish the fine structure and features of the anther development period, which can help accurately pinpoint the time and space in which fertility-related features appear. Wheat anthers were divided into 15 stages from stamen formation to anther senescence. The stages included precallose, central callose, meiotic, tetrad, young microspore, vacuolar microspore, among others [33]. The color of flower buds and state of flower dehiscence were observed in celery in comparison with wheat. This can be combined with anther length for cytological analysis. Anther development of Phyllostachys edulis can be classified into six stages: primary sporogenous cell, secondary sporogenous cell, microsporocyte, spore pull over period, mononuclear microspore, and mature pollen [34]. These stages of development are similar to those of celery, but the microspore cells of Phyllostachys edulis only undergo one mitosis, and mature pollen grains are mostly two-celled; while the microspore cells of celery undergo two mitoses, and mature pollen grains are three-celled.

\subsection{Genes that Regulate Physiological and Biochemical Processes during Flower Development}

Anther development is a complex process regulated by multiple genes. Several genes related to anther development were isolated from Arabidopsis, rice, tobacco, and other plant species. Their regulatory functions were identified as well. Studies in Arabidopsis found that TDF1 (DEFECTIVE IN TAPETAL DEVELOPMENT AND FUNCTION 1) and AMS (ABORTED MICROSPORE), which encodes a R2R3 MYB factor and a basic helix-loop-helix (bHLH) factor, respectively, can form a feed-forward loop (FFL) to continuously activate the expression of their regulatory targets [35]. Furthermore, GRF (GROWTH-REGULATING FACTOR) family members such as GRF1, GRF2, GRF3, and GRF5 play a key role in the regulation of carpel and anther development [35,36]. BnaC.CP20.1 plays an important role in tapetum degeneration and pollen wall formation in Arabidopsis [32]. HTH1(HOTHEAD-Like) is involved in keratin biosynthesis, anther development, and pollen fertility of rice [37]. EAT1 (ETERNAL TAPETUM1), belonging to bHLH, is a key regulatory factor that can trigger mitotic phase phasiRNA biogenesis in rice anthers, while NsylCBL10 promoter in tobacco is active in mature anthers $[38,39]$. In this study, numerous DEGs related to anthers development were screened during flower development by transcriptome sequencing technology, and a regulatory model for the anther development was constructed through functional annotation and expression analysis (Figure 8). In the GO annotation, early stages of flower development involved ribosomal-related biological processes. Following the completion of anther meiosis, the tapetum would begin to form precursors of sporopollenin, leading to ribosome synthesis of sporopollenin [40]. On the other hand, later stages of flower development involved biological processes of amino sugar metabolism, cytoplasm, threonine-type endopeptidase activity, and threonine-type peptidase activity, which is speculated to be related to the maturation of pollen grains [41]. KEGG annotation also showed differences at different developmental stages. Early stages of flower development largely included oxidative phosphorylation, TCA cycle, carbon fixation in photosynthetic organisms, pentose and glucuronate interconversions, glycolysis/gluconeogenesis, and other metabolic processes. These processes were mainly linked to plant photosynthesis, starch and sucrose metabolism. This is consistent with the evidence that anther 
development is associated with a decrease in photosynthesis rate and reduced chlorophyll content in anthers [41]. Accordingly, the rate of sucrose and starch metabolism also decreased with flower development [41]. In later stages, DEGs related to anther development were markedly enriched in some processes such as spliceosome, mRNA monitoring, protein processing, purine metabolism, and pyrimidine metabolism. Purines and pyrimidines are raw materials for nucleotide synthesis [42]. Studies have shown that microspores are closely associated with nucleotide metabolism and spliceosome is involved in the formation of pollen walls $[43,44]$. These results indicate that the maturation of pollen grains occurred at the later stage of flower development. Combined with the ribosomal-related biological processes and cytoplasm in GO annotation, carbon fixation in photosynthetic organisms, and purine and pyrimidine metabolism of KEGG, and the results of anther cytology research, it can be speculated that the early flower bud stage to the middle early flower bud stage may be related to the 3-5 stages of the anther stage, and the middle early flower bud stage to early flowering stage may be associated with the process of 5-9 stages. In summary, anthers of celery have a diverse appearance and diverse internal physiological and biochemical processes at various stages of development.

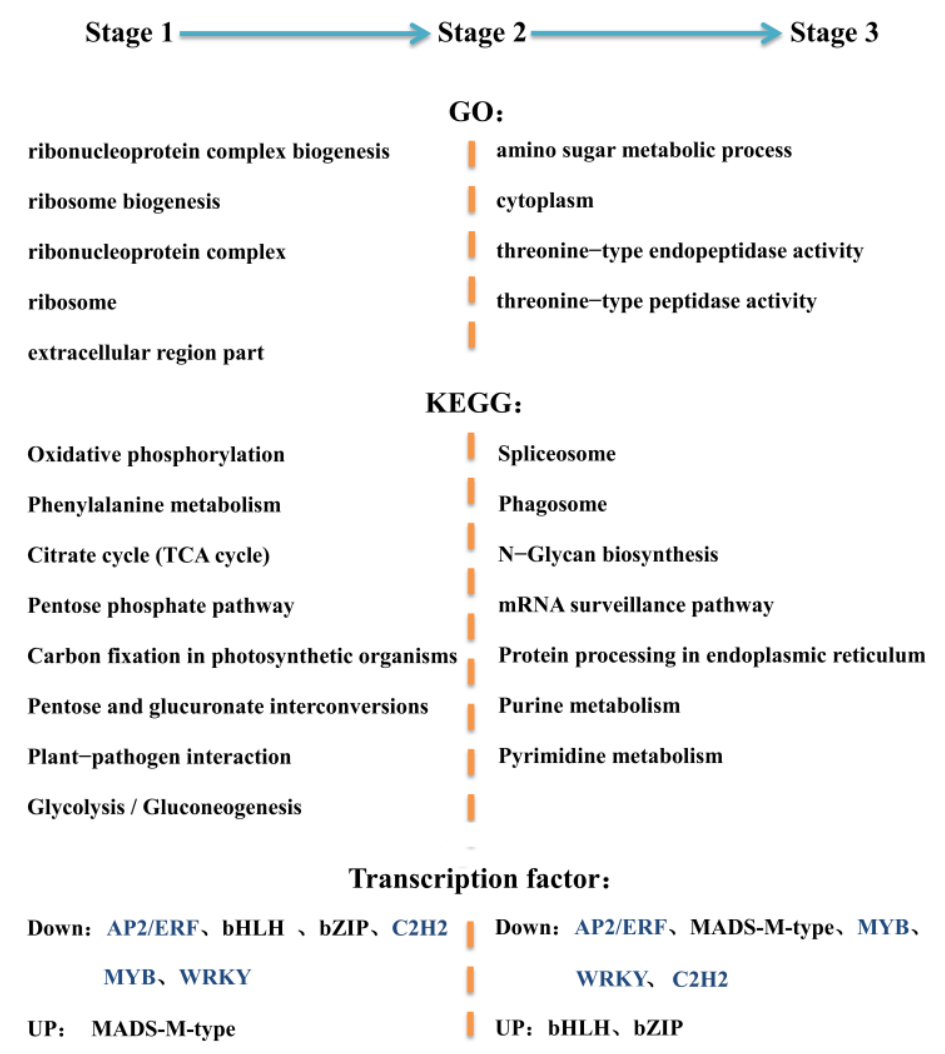

Figure 8. An overview of function and transcription factor family changes involved in celery anther development at the three flower developmental stages (S1, S2, S3). GO and KEGG both show different functions at different stages. The transcriptional abundance of transcription factor families with a consistent trend is shown in blue.

\subsection{Transcription Factor Families Show Different Regulation of Flower Development}

The regulatory effects of transcription factors at various stages were dissimilar (Figure 8). Of note, bHLH and bZIP were mainly downregulated in the early flower bud stage but upregulated in the early flowering stage. The expression levels of MADS-M-type genes were high in the early stage but low in the late stage. To further analyze the regulatory results of genes, AP2/ERF, WRKY, bZIP, and MADS-M-type were selected for verification based on the abundance of transcription factors and functional annotation results of differential genes. The majority of results obtained by qPCR were 
consistent with the transcriptome analysis, while discrepancies observed in some results may have been due to differences in sensitivity between the two techniques.

It was reported that transcription factors like AP2/ERF, WRKY, bZIP, and MADS-M-type are involved in the regulation of flower development. AP2 plays an extensive role by regulating the expression of numerous genes in flower organs [45]. For instance, the AP2 gene regulates the formation of perianth in Arabidopsis during the early stages of flower development [46]. In cotton, many GhWRKY genes show high expression levels during anther development, especially in the tetrad pollen (TTP) and uninucleate pollen (UNP) stages [47,48]. In this study, we found that Agr13446, Agr00157, and Agr14035 in the AP2/ERF family and Agr36822, Agr19214, and Agr14189 in the WRKY family had higher expression levels at the S1 stage, suggesting that these genes could play an important role in the early stages of anther development. TGA9 and TGA10, members of bZIP, played an important role in regulating the formation of tapetum and anther dehiscence in Arabidopsis [49]. The expression of Agr39039 of the bZIP family increased then later decreased in the three stages of flower development in celery. Ultimately, there was little change in expression levels in the three stages. It is speculated that Agr39039 plays a regulatory role in the process of anther development. MADS-M-type was a type I MADS-box gene. Previous studies showed that these genes are expressed in male and female gametophytes as well as during endosperm and embryo early development stages. However, they mainly regulate female gametophyte, endosperm, and embryo development [50-52]. AGL80, which belongs to MADS-M-type, plays an important regulatory role in the development of central cells and early endosperm, but it has no clear regulatory effect on male gametophytes [53,54]. AGL23 can regulate the formation of female gametophytes and organelles during embryonic development in Arabidopsis [55]. Studies have shown that transcription factors have important regulatory roles in the development of anthers, but the specific regulatory functions of some transcription factors were unclear. For example, MADS-M-type mainly regulates the development process of female gametes, and it had no obvious regulatory effect on male gametes. In this study, some genes in the MADS-M-type family (Agr08149, Agr37458) were highly expressed in the middle flower bud period. They may play an important role in the anther development regulatory network. SUP (SUPERMAN) in Arabidopsis encodes a C2H2 protein, participates in the process of controlling stamen cell proliferation during flower development, and has discrete upstream promoter elements required for early expression in stamen primordium. Studies on the anthers of petunia found that silencing TAZ1 (TAPETUM DEVELOPMENT ZINC FINGER PROTEIN1) leads to abnormal development and premature degeneration of the tapetum, resulting in microspore infertility [56]. In this study, the three genes (Agr04312, Agr28404, Agr30688) from C2H2 family all expressed at the highest level in S1 compared with S2 and S3, indicating that these genes may play a key role in the early stage of anther development in celery [57]. It was reported that the cause of celery male sterility is abnormal morphology of the tapetum before meiosis, and it is mainly due to the immediate degradation of the abnormal tapetum after tetrad stage [21]. The highest expression of $\mathrm{C} 2 \mathrm{H} 2$ in celery at $\mathrm{S} 1$ may be related to the abnormality of the tapetum and the male sterility of celery, while other transcription factor families like MYB and bHLH are also related to the formation and degradation of the tapetum. AtMYB103 is necessary for the development of tapetum in Arabidopsis, and bHLH transcription factor ETERNAL TAPETUM1 (EAT1) can regulate programmed cell death in the tapetum $[38,58]$. This study analyzed the development of celery anthers at histological and cytological levels, and linked it to changes in gene expression. The results provide a theoretical basis and excellent gene resources for germplasm improvement of celery and selection of new varieties. As for the genetic regulation mechanism of celery infertility, we could conduct in-depth research combined with the genome sequence of celery.

\section{Conclusions}

The purpose of this study was to carry out a cytological study and transcriptome analysis of celery anthers and identify the genes related to anther development. A total of 1074 differentially expressed genes were identified for flower development and could provide a reference for further 
research on specific genes related to anther development. In particular, transcription factors such as $\mathrm{C} 2 \mathrm{H} 2$, AP2/ERF, bZIP, WRKY, and MYB could play a key regulatory role in anther development. In addition, anther development involved physiological and biochemical processes such as ribosome metabolism, glucose metabolism and amino acid metabolism. In summary, these results provide a theoretical basis for molecular breeding of new celery varieties with pollen abortion and theoretical references for reproductive biology research of celery and Apiaceae family.

Supplementary Materials: The following are available online at http://www.mdpi.com/2073-4395/10/5/653/s1, Figure S1: Morphological characteristics of flowers at different developmental stages. Figure S2: GO function annotation of unigenes. Figure S3: KOG function annotation of unigenes. Figure S4: KEGG function annotation of unigenes. Table S1: Statistical results of success rate of gene annotation were obtained from seven databases. Table S2: The comprehensive list of genes with all the annotations from the relevant databases. Table S3: The complist of detailed information for screening of differentially expressed genes of in the three samples.

Author Contributions: Conceptualization, M.L. and H.T.; Data curation, S.T., Y.L. (Ya Luo), Y.Z. (Yong Zhang), and Y.W.; Formal analysis, G.T. and Y.Z. (Yunting Zhang); Funding acquisition, M.L. and H.T.; Investigation, Y.L. (Yuanxiu Lin), Q.C., and F.Z.; Writing—original draft, M.L. and S.T.; Writing—review and editing, B.S. and X.W. All authors have read and agreed to the published version of the manuscript.

Funding: This work was supported by the Shuangzhi project of Sichuan Agricultural University (03573134), Undergraduate Innovation Training Program (201810626019), and the Technology Support for Creation and Industrialization of New Vegetable Varieties in Guizhou Province [2017(5715)].

Conflicts of Interest: The authors declare no conflict of interest.

\section{References}

1. Parish, R.W.; Li, S.F. Death of a tapetum: A programme of developmental altruism. Plant Sci. 2010, 178, 73-89. [CrossRef]

2. Chen, L.; Liu, Y.-G. Male Sterility and Fertility Restoration in Crops. Annu. Rev. Plant Boil. 2014, 65, 579-606. [CrossRef] [PubMed]

3. Tester, M.; Langridge, P. Breeding Technologies to Increase Crop Production in a Changing World. Science 2010, 327, 818-822. [CrossRef] [PubMed]

4. Zhou, X.; Liu, Z.; Ji, R.; Feng, H. Comparative transcript profiling of fertile and sterile flower buds from multiple-allele-inherited male sterility in Chinese cabbage (Brassica campestris L. ssp. pekinensis). Mol. Genet. Genom. 2017, 292, 967-990. [CrossRef]

5. Müller, M.; Katsov, K.; Schick, M. A New Mechanism of Model Membrane Fusion Determined from Monte Carlo Simulation. Biophys. J. 2003, 85, 1611-1623. [CrossRef]

6. Tang, H.; Xie, Y.; Liu, Y.-G.; Chen, L. Advances in understanding the molecular mechanisms of cytoplasmic male sterility and restoration in rice. Plant Reprod. 2017, 30, 179-184. [CrossRef]

7. Huang, X.; Yue, Y.; Sun, J.; Peng, H.; Yang, Z.; Bao, M.; Hu, H. Characterization of a fertility-related SANT/MYB gene (PhRL) from petunia. Sci. Hortic. 2015, 183, 152-159. [CrossRef]

8. Meng, N.; He, M.; Bai, Y.; Xu, H.; Dandekar, A.M.; Fei, Z.; Cheng, L. Decreased sorbitol synthesis leads to abnormal stamen development and reduced pollen tube growth via an MYB transcription factor, MdMYB39L, in apple (Malus domestica). New Phytol. 2017, 217, 641-656. [CrossRef]

9. Wang, T.; Ping, X.; Cao, Y.; Jian, H.; Gao, Y.; Wang, J.; Tan, Y.; Xu, X.; Lu, K.; Li, J.; et al. Genome-wide exploration and characterization of miR172/euAP2 genes in Brassica napus L. for likely role in flower organ development. BMC Plant Boil. 2019, 19, 336. [CrossRef]

10. Yu, Y.; Liu, Z.; Wang, L.; Kim, S.-G.; Seo, P.J.; Qiao, M.; Wang, N.; Li, S.; Cao, X.; Park, C.-M.; et al. WRKY71 accelerates flowering via the direct activation ofFLOWERING LOCUS TandLEAFYinArabidopsis thaliana. Plant J. 2015, 85, 96-106. [CrossRef]

11. Liu, H.; Sun, M.; Du, N.; Pan, H.; Cheng, T.; Wang, J.; Zhang, Q. Whole-Transcriptome Analysis of Differentially Expressed Genes in the Vegetative Buds, Floral Buds and Buds of Chrysanthemum morifolium. PLoS ONE 2015, 10, e0128009. [CrossRef] [PubMed]

12. Noor, S.H.; Ushijima, K.; Murata, A.; Yoshida, K.; Tanabe, M.; Tanigawa, T.; Kubo, Y.; Nakano, R. Double flower formation induced by silencing of C-class MADS-box genes and its variation among petunia Cultivars. Sci. Hortic. 2014, 178, 1-7. [CrossRef] 
13. Chen, Z.-S.; Liu, X.-F.; Wang, D.-H.; Chen, R.; Zhang, X.-L.; Xu, Z.-H.; Bai, S.-N. Transcription Factor OsTGA10 Is a Target of the MADS Protein OsMADS8 and Is Required for Tapetum Development. Plant Physiol. 2017, 176, 819-835. [CrossRef] [PubMed]

14. Dinneny, J.R.; Weigel, D.; Yanofsky, M.F. NUBBIN and JAGGED define stamen and carpel shape in Arabidopsis. Development 2006, 133, 1645-1655. [CrossRef]

15. Li, M.-Y.; Feng, K.; Hou, X.-L.; Jiang, Q.; Xu, Z.-S.; Wang, G.-L.; Liu, J.-X.; Wang, F.; Xiong, A.-S. The genome sequence of celery (Apium graveolens L.), an important leaf vegetable crop rich in apigenin in the Apiaceae family. Hortic. Res. 2020, 7, 1-10. [CrossRef]

16. Li, M.-Y.; Wang, F.; Jiang, Q.; Wang, G.-L.; Tian, C.; Xiong, A.-S. Validation and Comparison of Reference Genes for qPCR Normalization of Celery (Apium graveolens) at Different Development Stages. Front. Plant Sci. 2016, 7, 5245. [CrossRef]

17. Kooti, W.; Aliakbari, S.; Asadi-Samani, M.; Ghadery, H.; Ashtary-larky, D. A review on medicinal plant of Apium graveolens. Adv. Herb. Med. 2015, 1, 48-59.

18. Nagella, P.; Ahmad, A.; Kim, S.-J.; Chung, I.-M. Chemical composition, antioxidant activity and larvicidal effects of essential oil from leaves of Apium graveolens. Immunopharmacol. Immunotoxicol. 2011, 34, $205-209$. [CrossRef]

19. Bruznican, S.; De Clercq, H.; Eeckhaut, T.; Van Huylenbroeck, J.; Geelen, D. Celery and Celeriac: A Critical View on Present and Future Breeding. Front. Plant Sci. 2020, 10, 1699. [CrossRef]

20. Li, M.-Y.; Hou, X.; Wang, F.; Tan, G.-F.; Xiong, A.-S.; Xiong, A.-S. Advances in the research of celery, an important Apiaceae vegetable crop. Crit. Rev. Biotechnol. 2017, 38, 172-183. [CrossRef]

21. Quiros, C.F.; Rugama, A.; Dong, Y.Y.; Orton, T.J. Cytological and genetical studies of a male sterile celery. Euphytica 1986, 35, 867-875. [CrossRef]

22. Gao, G.; Jin, L.; Lu, F.; Lu, Z.; Ren, Z.; Yu, H. Genetic Characters of 01-3A Male Sterile Celery. J. Changjiang Veg. 2009, 21-23. [CrossRef]

23. Jia, X.-L.; Wang, G.-L.; Xiong, F.; Yu, X.-R.; Xu, Z.-S.; Wang, F.; Xiong, A.-S. De novo assembly, transcriptome characterization, lignin accumulation and anatomic characteristics: Novel insights into lignin biosynthesis during celery leaf development. Sci. Rep. 2015, 5, 8259. [CrossRef]

24. Grabherr, M.; Mauceli, E.; Ma, L.-J. Genome Sequencing and Assembly. Adv. Struct. Saf. Stud. 2011, 722, 1-9.

25. Davidson, N.; Oshlack, A. Corset: Enabling differential gene expression analysis for. Genome Boil. 2014, 15, 410. [CrossRef]

26. I Love, M.; Huber, W.; Anders, S. Moderated estimation of fold change and dispersion for RNA-seq data with DESeq2. Genome Biol. 2014, 15, 002832. [CrossRef] [PubMed]

27. Jin, J.; He, K.; Tang, X.; Li, Z.; Lv, L.; Zhao, Y.; Luo, J.; Gao, G. An Arabidopsis Transcriptional Regulatory Map Reveals Distinct Functional and Evolutionary Features of Novel Transcription Factors. Mol. Boil. Evol. 2015, 32, 1767-1773. [CrossRef] [PubMed]

28. Pfaffl, M. A new mathematical model for relative quantification in real-time RT-PCR. Nucleic Acids Res. 2001, 29, 45. [CrossRef] [PubMed]

29. Goldberg, R.B.; Beals, T.P.; Sanders, P.M. Anther development: Basic principles and practical applications. Plant Cell 1993, 5, 1217-1229. [CrossRef] [PubMed]

30. Trapalis, M.; Li, S.F.; Parish, R.W. The Arabidopsis GASA10 gene encodes a cell wall protein strongly expressed in developing anthers and seeds. Plant Sci. 2017, 260, 71-79. [CrossRef]

31. Wu, H.-M.; Cheung, A.Y. Programmed cell death in plant reproduction. Plant Mol. Boil. 2000, 44, $267-281$. [CrossRef] [PubMed]

32. Song, L.; Zhou, Z.; Tang, S.; Zhang, Z.; Xia, S.; Qin, M.; Li, B.; Wen, J.; Yi, B.; Shen, J.; et al. Ectopic Expression ofBnaC.CP20.1Results in Premature Tapetal Programmed Cell Death in Arabidopsis. Plant Cell Physiol. 2016, 57, 1972-1984. [CrossRef] [PubMed]

33. Browne, R.; Iacuone, S.; Li, S.F.; Dolferus, R.; Parish, R.W. Anther Morphological Development and Stage Determination in Triticum aestivum. Front. Plant Sci. 2018, 9, 228. [CrossRef] [PubMed]

34. Zhou, J.M.; Sun, L.F.; Feng, Y.; Lian, C.; Hong, R.; Zhang, Y.; Guo, Q.R. Observation on anther development of Phyllostachys edulis. Guihaia 2016, 36, 231-235. [CrossRef]

35. Lou, Y.; Zhou, H.; Han, Y.; Zeng, Q.; Zhu, J.; Yang, Z.-N. Positive regulation of AMS by TDF1 and the formation of a TDF1-AMS complex are required for anther development in Arabidopsis thaliana. New Phytol. 2017, 217, 378-391. [CrossRef] 
36. Lee, S.J.; Lee, B.H.; Jung, J.H.; Park, S.K.; Song, J.T.; Kim, J.H. GROWTH-REGULATING FACTOR and GRF-INTERACTING FACTOR Specify Meristematic Cells of Gynoecia and Anthers. Plant Physiol. 2017, 176, 717-729. [CrossRef]

37. Xu, Y.; Liu, S.; Ling, S.; Chen, C.; Yao, J. HOTHEAD-Like HTH1 is Involved in Anther Cutin Biosynthesis and is Required for Pollen Fertility in Rice. Plant Cell Physiol. 2017, 58, 1238-1248. [CrossRef]

38. Ono, S.; Liu, H.; Tsuda, K.; Fukai, E.; Tanaka, K.; Sasaki, T.; Nonomura, K.-I. EAT1 transcription factor, a non-cell-autonomous regulator of pollen production, activates meiotic small RNA biogenesis in rice anther tapetum. PLoS Genet. 2018, 14, e1007238. [CrossRef]

39. Mao, J.J.; Wang, Q.; Shi, S.J.; Zhang, G.; Xu, D.Z.; Li, S.G.; Liu, H.B. Cloning and functional analysis of NsylCBL10 promoter in Nicotiana sylvestris. Acta Tab. Sin. 2017, 23, 97-105, 120. [CrossRef]

40. Dickinson, H.G.; Bell, P.R. The Changes in the Tapetum of Pinus banksiana Accompanying Formation and Maturation of the Pollen. Ann. Bot. 1976, 40, 1101-1109. [CrossRef]

41. Yue, Y.; Tian, S.; Wang, Y.; Ma, H.; Liu, S.; Wang, Y.; Hu, H. Transcriptomic and GC-MS Metabolomic Analyses Reveal the Sink Strength Changes during Petunia Anther Development. Int. J. Mol. Sci. 2018, $19,955$. [CrossRef] [PubMed]

42. Stasolla, C.; Katahira, R.; Thorpe, T.A.; Ashihara, H. Purine and pyrimidine nucleotide metabolism in higher plants. J. Plant Physiol. 2003, 160, 1271-1295. [CrossRef] [PubMed]

43. Nguyen, T.D.; Moon, S.; Nguyen, V.N.T.; Gho, Y.; Chandran, A.K.N.; Soh, M.-S.; Song, J.T.; An, G.; Oh, S.A.; Park, S.K.; et al. Genome-wide identification and analysis of rice genes preferentially expressed in pollen at an early developmental stage. Plant Mol. Boil. 2016, 92, 71-88. [CrossRef] [PubMed]

44. Huang, X.-Y.; Niu, J.; Sun, M.-X.; Zhu, J.; Gao, J.-F.; Yang, J.; Zhou, Q.; Yang, Z.-N. CYCLIN-DEPENDENT KINASE G1 is associated with the spliceosome to regulate CALLOSE SYNTHASE5 splicing and pollen wall formation in Arabidopsis. Plant Cell 2013, 25, 637-648. [CrossRef]

45. Krogan, N.T.; Hogan, K.; Long, J.A. APETALA2 negatively regulates multiple floral organ identity genes in Arabidopsis by recruiting the co-repressor TOPLESS and the histone deacetylase HDA19. Development 2012, 139, 4180-4190. [CrossRef]

46. Kunst, L.; Klenz, J.E.; Martinez-Zapater, J.; Haughn, G.W. AP2 Gene Determines the Identity of Perianth Organs in Flowers of Arabidopsis thaliana. Plant Cell 1989, 1, 1195-1208. [CrossRef]

47. Dou, L.; Zhang, X.; Pang, C.; Song, M.; Wei, H.; Fan, S.; Yu, J. Genome-wide analysis of the WRKY gene family in cotton. Mol. Genet. Genom. 2014, 289, 1103-1121. [CrossRef]

48. Ma, J.; Wei, H.; Liu, J.; Song, M.; Pang, C.; Wang, L.; Zhang, W.; Fan, S.; Yu, J. Selection and Characterization of a Novel Photoperiod-Sensitive Male Sterile Line in Upland Cotton. J. Integr. Plant Boil. 2013, 55, 608-618. [CrossRef]

49. Murmu, J.; Bush, M.J.; Delong, C.; Li, S.; Xu, M.; Khan, M.; Malcolmson, C.; Fobert, P.R.; Zachgo, S.; Hepworth, S.R. Arabidopsis basic leucine-zipper transcription factors TGA9 and TGA10 interact with floral glutaredoxins ROXY1 and ROXY2 and are redundantly required for anther development. Plant Physiol. 2010, 154, 1492-1504. [CrossRef]

50. Tiwari, S.; Spielman, M.; Schulz, R.; Oakey, R.; Kelsey, G.; Salazar, A.; Zhang, K.; Pennell, R.; Scott, R.J. Transcriptional profiles underlying parent-of-origin effects in seeds of Arabidopsis thaliana. BMC Plant Boil. 2010, 10, 72. [CrossRef]

51. Walia, H.; Josefsson, C.; Dilkes, B.P.; Kirkbride, R.; Harada, J.; Comai, L. Dosage-dependent deregulation of an AGAMOUS-LIKE gene cluster contributes to interspecific incompatibility. Curr. Boil. 2009, 19, 1128-1132. [CrossRef] [PubMed]

52. Day, R.C.; Herridge, R.P.; Ambrose, B.A.; Macknight, R. Transcriptome Analysis of Proliferating Arabidopsis Endosperm Reveals Biological Implications for the Control of Syncytial Division, Cytokinin Signaling, and Gene Expression Regulation[C][W][OA]. Plant Physiol. 2008, 148, 1964-1984. [CrossRef]

53. Portereiko, M.F.; Lloyd, A.; Steffen, J.G.; Punwani, J.A.; Otsuga, D.; Drews, G.N. AGL80 Is Required for Central Cell and Endosperm Development in Arabidopsis[W]. Plant Cell 2006, 18, 1862-1872. [CrossRef] [PubMed]

54. Masiero, S.; Colombo, L.; Grini, P.; Schnittger, A.; Kater, M. The Emerging Importance of Type I MADS Box Transcription Factors for Plant Reproduction. Plant Cell 2011, 23, 865-872. [CrossRef] [PubMed] 
55. Colombo, M.; Masiero, S.; Vanzulli, S.; Lardelli, P.; Kater, M.; Colombo, L. AGL23, a type I MADS-box gene that controls female gametophyte and embryo development in Arabidopsis. Plant J. 2008, 54, 1037-1048. [CrossRef] [PubMed]

56. Kapoor, S.; Kobayashi, A.; Takatsuji, H. Silencing of the Tapetum-Specific Zinc Finger Gene TAZ1 Causes Premature Degeneration of Tapetum and Pollen Abortion in Petunia. Plant Cell 2002, 14, 2353-2367. [CrossRef] [PubMed]

57. Ito, T.; Sakai, H.; Meyerowitz, E.M. Whorl-Specific Expression of the SUPERMAN Gene of Arabidopsis Is Mediated by cis Elements in the Transcribed Region. Curr. Boil. 2003, 13, 1524-1530. [CrossRef]

58. Higginson, T.; Li, S.F.; Parish, R.W. AtMYB103 regulates tapetum and trichome development in Arabidopsis thaliana. Plant J. 2003, 35, 177-192. [CrossRef]

(C) 2020 by the authors. Licensee MDPI, Basel, Switzerland. This article is an open access article distributed under the terms and conditions of the Creative Commons Attribution (CC BY) license (http://creativecommons.org/licenses/by/4.0/). 